\title{
Achieving the earliest possible reperfusion in patients with acute coronary syndrome: a current overview
}

Takahiro Nakashima and Yoshio Tahara*

\begin{abstract}
Acute coronary syndrome (ACS) remains one of the leading causes of mortality worldwide. Appropriate management of ACS will lead to a lower incidence of cardiac arrest. Percutaneous coronary intervention (PCI) is the first-line treatment for patients with ACS. PCI techniques have become established. Thus, the establishment of a system of health care in the prehospital and emergency department settings is needed to reduce mortality in patients with ACS. In this review, evidence on how to achieve earlier diagnosis, therapeutic intervention, and decision to reperfuse with a focus on the prehospital and emergency department settings is systematically summarized.

The purpose of this review is to generate current, evidence-based consensus on scientific and treatment recommendations for health care providers who are the initial points of contact for patients with signs and symptoms suggestive of ACS.
\end{abstract}

Keywords: ACS, STEMI, NSTEMI, PCI

\section{Background}

Acute coronary syndrome (ACS) remains one of the leading causes of mortality worldwide. Appropriate management of this disease will lead to a reduced incidence of cardiac arrest. One major focus of research worldwide is improving outcomes in patients with ACS. In 2015, the Japan Resuscitation Council (JRC) guidelines were updated based on the 2015 International Consensus on Cardiopulmonary Resuscitation and Cardiovascular Care Science with Treatment Recommendations (CoSTR). CoSTR is a systematic and explicit approach to making judgments about the quality of evidence and strength of recommendations. The purpose of this review is to generate current, evidence-based consensus on scientific and treatment recommendations for health care providers who are the initial point of contact for patients with signs and symptoms suggestive of ACS based on the 2015 JRC guidelines.
* Correspondence: tahara@ncvc.go.jp

Department of Cardiovascular Medicine, National Cerebral and

Cardiovascular Center, 5-7-1 Fujishirodai, Suita 565-8565, Japan

\section{Review}

Primary health care algorithm for ACS

Figure 1 shows the primary algorithm for ACS. In patients presenting to the emergency department (ED) with chest pain of suspected cardiac etiology, prompt diagnosis and treatment of ACS are the key concepts. The urgency and severity of ACS are evaluated using the history and physical examination in the ED. Twelve-lead electrocardiogram (ECG) plays a central role in the triage process. For patients with ST-elevation myocardial infarction (STEMI), the physician cooperates with the cardiologist to prioritize revascularization. On the other hand, for patients with no ST elevation but non-STEMI (NSTEMI) or high-risk unstable angina is suspected, the emergency physician and cardiologist should work together on cardiac care unit admission. These patients have a high rate of adverse cardiac events (death, nonfatal myocardial infarction, and urgent revascularization). Thus, an invasive strategy such as percutaneous coronary intervention (PCI) is often selected in addition to medical therapy. In patients with suspected ACS, normal initial biomarkers and nonischemic ECG, $0 \mathrm{~h} / 1 \mathrm{~h}$ or $0 \mathrm{~h} / 3 \mathrm{~h}$ rule-out algorithm of NSTEMI using high-sensitivity cardiac troponin (hs-cTn) may be recommended as a safe and effective strategy in the 


\section{Acute Coronary Syndrome}

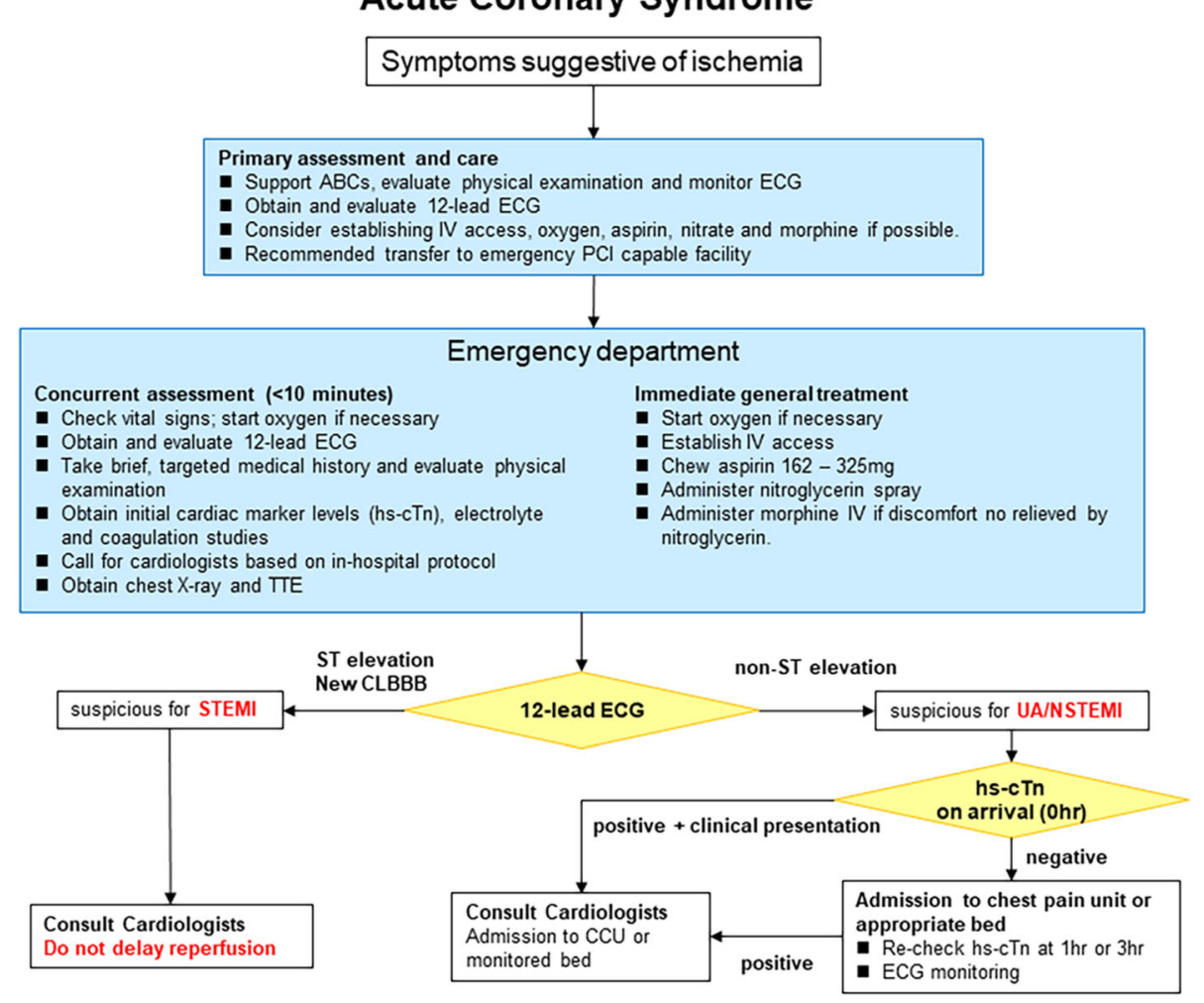

Fig. 1 Primary health care algorithm for acute coronary syndrome. ABC airway, breathing, and circulation; CCU cardiac care unit; CLBBB complete left bundle block; ECG electrocardiogram; EMS emergency medical services; $h s$-cTn high-sensitivity cardiac troponin; IV intravenous; MI myocardial infarction; $\mathrm{PCl}$ percutaneous coronary intervention; TTE transthoracic echocardiography; UA unstable angina

ED (see the "Biomarkers in ACS" section). Transthoracic echocardiography is helpful not only in the evaluation of wall motion abnormality, left ventricular function, and mechanical complications such as ventricular free wall rupture, ventricular septal perforation, and papillary muscle rupture, but also in the diagnosis of conditions such as acute aortic dissection, acute pulmonary embolism, and acute pericarditis. Chest X-ray is helpful in diagnosing and assessing the severity of ACS, but is not always necessary if ACS is strongly suspected and obtaining a chest X-ray will delay revascularization. Furthermore, waiting for the results of laboratory data to diagnose ACS should not cause delay in revascularization. Time from hospital arrival to transport to facilities capable of performing emergency PCI capable should be within $30 \mathrm{~min}$.

\section{Diagnostic interventions in ACS Risk stratification in ACS}

Various patient demographic factors might impede seeking medical help rapidly and add to further in-hospital treatment delay. Many reports have suggested that older age, female gender, racial or ethnic minority status, low socioeconomic status, and residing alone are independent factors associated with in-hospital treatment delay
$[1,2]$. Providers should be trained to expeditiously identify patients with ACS irrespective of age, gender, socioeconomic status, or living arrangement. On the other hand, signs and symptoms may be useful in combination with other important information such as biomarkers, risk factors, ECG, and other diagnostic test results, in triaging and making some treatment and investigational decisions for ACS in the out-of-hospital and ED settings. The Global Registry of Acute Coronary Events (GRACE) score provides accurate stratification of risk on admission and discharge (Table 1) [3, 4].

\section{ECG}

The ECG is essential for the initial triage and initiation of management in patients with possible ACS, especially in the ED and out-of-hospital settings. Many observational studies have shown the benefit of prehospital 12-lead ECG in reducing 30-day mortality, first-medical contact-to-reperfusion time, door-to-balloon time, and door-to-needle time compared with no ECG in patients with STEMI [5-13]. The 2015 JRC guidelines recommend prehospital 12-lead ECG acquisition with hospital notification for adult patients with suspected STEMI (strong recommendation, low-quality evidence). However, 
Table 1 The Global Registry of Acute Coronary Events (GRACE) score

\begin{tabular}{|c|c|c|c|c|c|c|c|c|c|c|c|}
\hline & Score & & Score & & Score & & Score & & Score & & Score \\
\hline Age (year) & & Heart rate (bpm) & & Systolic BP (mmHg) & & Killip class & & Creatinine $(\mathrm{mg} / \mathrm{dL})$ & & & \\
\hline$<40$ & 0 & $<70$ & 0 & $<80$ & 63 & Class I & 0 & $0.0-0.39$ & 2 & \multirow{2}{*}{$\begin{array}{l}\text { Cardiac arrest at } \\
\text { admission }\end{array}$} & \multirow[t]{2}{*}{43} \\
\hline $40-49$ & 18 & $70-89$ & 7 & $80-99$ & 58 & Class II & 21 & $0.4-0.79$ & 5 & & \\
\hline $50-59$ & 36 & 90-109 & 13 & $100-119$ & 47 & Class III & 43 & $0.8-1.19$ & 8 & \multirow{2}{*}{$\begin{array}{l}\text { Elevated cardiac } \\
\text { markers }\end{array}$} & \multirow[t]{2}{*}{15} \\
\hline $60-69$ & 55 & $110-149$ & 23 & $120-139$ & 37 & Class IV & 64 & $1.2-1.59$ & 11 & & \\
\hline 70-79 & 73 & 150-199 & 36 & $140-159$ & 26 & & & $1.6-1.99$ & 14 & \multirow{3}{*}{$\begin{array}{l}\text { ST-segment } \\
\text { deviation }\end{array}$} & \multirow[t]{3}{*}{30} \\
\hline $80<$ & 91 & $200<$ & 46 & $160-199$ & 11 & & & $2.0-3.99$ & 23 & & \\
\hline & & & & $200<$ & 0 & & & $4.0<$ & 31 & & \\
\hline
\end{tabular}

In-hospital mortality: low risk $(\leq 10)$, intermediate risk (109-140), and high risk ( $>140)$ are $<1 \%, 1-3 \%$, and $>3 \%$, respectively. Post-discharge to 6 months death: low risk ( $\leq 88)$, intermediate risk (89-118), and high risk $(>8)$ are $<3 \%, 3-8 \%$, and $>8 \%$, respectively $B P$ blood pressure

prehospital 12-lead ECG is not currently widespread in Japan. Thus, we should consider the use of prehospital 12-lead ECG in order to start specific therapy for STEMI more quickly. At the same time, we need to develop a computer-assisted ECG interpretation system for STEMI and an educational program for nurses and paramedics in ECG interpretation for STEMI [14-18].

\section{Biomarkers in ACS}

Some observational studies have shown that hs-cTn is helpful for excluding the diagnosis of ACS [19-26]. The 2015 JRC guidelines recommend against using only hscTnT and hs-cTnI measured at 0 and $2 \mathrm{~h}$ to rule out ACS (strong recommendation, very low-quality evidence). However, in low-risk patients (as defined by the Vancouver rule or a Thrombolysis in Myocardial Infarction Trial [TIMI] score of 0 or 1), the guidelines suggest that negative hs-cTnI at 0 and $2 \mathrm{~h}$ and negative hs-cTnI or hs-cTnT at 0 and 3-6 h may be used to rule out ACS (weak recommendation, low-quality evidence). Further studies are needed to evaluate the combination of troponins and clinical risk scores to determine which patients with chest pain may be safely discharged from the ED.

\section{Imaging techniques}

Noninvasive tests such as cardiac computed tomography (CT), cardiac magnetic resonance (MR), myocardial perfusion imaging, and echocardiography may be considered in selected patients who present to the ED with chest pain and an initial nondiagnostic conventional work-up that included 12-lead ECG or cardiac biomarkers. It is reasonable to consider both radiation and iodinated contrast exposure when using cardiac CT and myocardial perfusion imaging. Moreover, in some lowrisk patients, these noninvasive tests may decrease cost, length of stay, and time to diagnosis [27-29]. They might provide valuable short-term and long-term prognostic information on future major cardiac events.
However, there are insufficient data to assess the impact of imaging techniques on mortality. A combination of these techniques and chest pain observation units may be useful, and the spread of chest pain observation units is expected in Japan.

\section{Therapeutic interventions for ACS Oxygen therapy}

Some randomized controlled trials (RCTs) have shown no difference between no oxygen and supplementary oxygen administration with regards to mortality (odds ratio $[\mathrm{OR}], 0.91 ; 95 \%$ confidence interval $[\mathrm{CI}], 0.25-3.34$ ) [30-34]. The 2015 JRC guidelines suggest withholding routine high-concentration oxygen supplementation $(8 \mathrm{~L} / \mathrm{min})$ in normoxic $\left(\mathrm{SpO}_{2}>93 \%\right)$ patients with $\mathrm{ACS}$ (weak recommendation, very low-quality evidence), except for patients with previous myocardial infarction, severe chronic obstructive pulmonary disease, respiratory failure, cardiogenic shock, central cyanosis, $\mathrm{SpO}_{2}<85 \%$, or dyspnea from any other cause. Moreover, two recent RCTs show that routine supplementary oxygen administration is not beneficial [33, 35]. However, there is lack of evidence regarding low-concentration oxygen supplementation.

\section{Nitroglycerin}

Although it is reasonable to consider early administration of nitroglycerin in selected patients without contraindications, insufficient evidence exists to support or refute the routine administration of nitroglycerin in the ED or prehospital setting in patients with suspected ACS. There may be some benefit if nitroglycerin results in pain relief. When non-cardiologist physicians administer nitroglycerin, they give one sublingual nitroglycerin tablet or spray every 3 to $5 \mathrm{~min}$, which may be repeated a total of 3 times if the patient remains hemodynamically stable. If right ventricular (RV) infarction is suspected, vasodilators, including nitroglycerin, are contraindicated because hemodynamic status with RV 
infarction depends on RV filling pressure. Relief of chest discomfort with nitroglycerin is neither sensitive nor specific for ACS; gastrointestinal etiologies as well as other causes of chest discomfort can respond to nitroglycerin administration.

\section{Analgesics and sedation}

Morphine can relieve chest pain, alleviate the work of breathing, reduce anxiety, and favorably affect ventricular loading conditions [36]. Despite limited direct evidence to support or refute the practice, morphine should be administered intravenously and titrated to pain relief in patients with STEMI. Morphine may be considered for pain relief in patients with suspected NSTEMI. Physicians give patients morphine 2 to $4 \mathrm{mg}$ via intravenous injection, which may be increased to $8 \mathrm{mg}$ every 5 to $15 \mathrm{~min}$ if it is not effective [37]. Other forms of analgesia (e.g., buprenorphine 0.1 to $0.2 \mathrm{mg}$ ) should be considered for patients with active chest discomfort. While anxiolytics may be administered to patients with ACS to alleviate anxiety, there is no evidence that anxiolytics facilitate ECG resolution, reduce infarct size, or decrease mortality in patients with suspected ACS. Non-steroidal anti-inflammatory drugs (NSAIDs) should not be administered because they may be harmful in patients with suspected ACS. Some studies have shown that NSAIDs are associated with an increased risk of mortality, reinfarction, hypertension, heart failure, and myocardial rupture in patients with STEMI [38, 39]. Patients with suspected ACS who are taking NSAIDs should have them discontinued when feasible.

\section{Aspirin (acetylsalicylic acid) and adenine diphosphate (ADP) receptor antagonists}

Despite limited direct evidence to support or refute the practice [40], the 2015 CoSTR guidelines mentioned that it may be reasonable to consider aspirin as soon as possible, without a history to exclude a true allergy or bleeding disorder. Moreover, some RCTs have shown that compared with in-hospital administration, there is no additional benefit with prehospital administration of an ADP receptor antagonist in terms of 30-day mortality (OR, 1.58; 95\% CI, 0.90-2.78) and major bleeding (OR, 1.12; 95\% CI, 0.72-1.74) [41-43]. These studies suggest that ADP receptor antagonists can be given to patients with suspected STEMI and planned primary PCI in either the prehospital or the in-hospital setting (very lowquality evidence, weak recommendation). However, in Japan, administration of aspirin for suspected STEMI outside of the hospital by emergency medical service (EMS) personnel is prohibited by law. When a primary $\mathrm{PCI}$ approach is being planned, physicians can give patients aspirin (162 to $325 \mathrm{mg}$ ) and ADP receptor antagonists (clopidogrel $300 \mathrm{mg}$ or prasugrel $20 \mathrm{mg}$ ). Further investigation is needed to confirm the benefit of prehospital aspirin and ADP receptor antagonist administration in the doctor car or medical helicopter.

\section{Anticoagulants}

In patients with suspected out-of-hospital STEMI, a non-RCT showed no benefit of prehospital unfractionated heparin (UFH) on 30-day mortality compared with in-hospital UFH (OR, 1.07; 95\% CI, 0.595-1.924) [44]. The 2015 CoSTR guidelines suggest that UFH administration can occur in either the prehospital or in-hospital setting in patients with suspected STEMI and a planned primary PCI approach. There is insufficient evidence to change existing practice (weak recommendation, very low-quality evidence). However, in Japan, EMS personnel cannot administer anticoagulants in the prehospital setting. Further investigation is needed to confirm the benefit of prehospital fibrinolysis in the doctor car or medical helicopter. Physicians administer UFH as a single intravenous injection with a target activated clotting time (ACT) of $>250 \mathrm{~s}$. We note that most evidence about UFH in patients ACS were from the pre-primary PCI era. Further investigation is needed to approve prehospital anticoagulant administration by EMS personnel and the use of enoxaparin for STEMI in Japan.

\section{Reperfusion decisions in patients with STEMI}

The 2015 JRC guidelines address the question of which reperfusion strategy is best under specific circumstances. The options available for reperfusion will depend on the local prehospital system and availability of PCI centers. They consider reperfusion decisions in relation to regional availability (e.g., prehospital fibrinolysis versus ED or prehospital fibrinolysis versus direct transport to PCI). Table 2 shows the most appropriate reperfusion strategy by time from symptom onset and anticipated treatment delay.

Table 2 Most appropriate reperfusion strategy by time from symptom onset and anticipated treatment delays

\begin{tabular}{llll}
\hline Treatment & \multicolumn{3}{l}{ Time from symptom onset } \\
\cline { 2 - 4 } & $<2 \mathrm{~h}$ & $2-3 \mathrm{~h}$ & $3-6 \mathrm{~h}^{*}$ \\
\hline$<60$ min & Primary PCl & Primary PCl or fibrinolysis ${ }^{\dagger}$ & Primary PCl $^{\dagger}$ \\
$60-120$ min & Fibrinolysis $^{\dagger}$ & Primary PCl or fibrinolysis $^{\dagger}$ & Primary PCl $^{\dagger}$ \\
$>120$ min & Fibrinolysis $^{\dagger}$ & Fibrinolysis $^{\dagger}$ & Fibrinolysis $^{\dagger}$
\end{tabular}

Patients with higher risk, including those with Killip class $>1$, may benefit from primary $\mathrm{PCl}$ even when there are treatment delays up to $120 \mathrm{~min}$ $\mathrm{PCl}$ percutaneous coronary intervention

*If time from symptom onset is greater than $6 \mathrm{~h}$, primary $\mathrm{PCl}$ is appropriate regardless of treatment delay

${ }^{\dagger}$ In case of fibrinolytic therapy, immediate transfer to a $\mathrm{PCl}$ center after fibrinolysis should be considered for cardiac angiography within 3 to $24 \mathrm{~h}$ 


\section{Prehospital fibrinolysis versus ED fibrinolysis}

Some RCTs have shown that prehospital fibrinolysis reduced in-hospital mortality without increasing intracranial hemorrhage and bleeding compared with in-hospital fibrinolysis (OR, 0.46; 95\% CI, 0.23-0.93) [44-47]. When fibrinolysis is the planned treatment strategy, the 2015 JRC guidelines recommend prehospital fibrinolysis over in-hospital fibrinolysis for STEMI in health systems where typical transport time is greater than $30 \mathrm{~min}$ and prehospital fibrinolysis can be accomplished by a physician in the ambulance or medical helicopter with wellestablished protocols, comprehensive training programs, and quality assurance programs in place (strong recommendation, moderate-quality evidence).

\section{Prehospital triage to a $\mathrm{PCl}$ center versus prehospital fibrinolysis}

There is moderate-quality evidence that mortality is not reduced and low-quality evidence of harm from fibrinolysis [48, 49]. The 2015 JRC guidelines suggest that direct triage and transport for PCI is preferred in geographic regions where PCI facilities are not available (weak recommendation, low-quality evidence). On the other hand, the 2015 CoSTR suggest that prehospital fibrinolysis is a reasonable alternative to triage and direct transport to a PCI center in geographic regions where PCI facilities are not available. In Japan, prehospital fibrinolysis is preferred but a physician must be present because only physicians can perform fibrinolysis. Further investigation is needed to confirm the benefit of prehospital fibrinolysis in the doctor car or medical helicopter.

\section{Delayed $\mathrm{PCl}$ versus fibrinolysis stratified by time since symptom onset}

Some RCTs have shown that compared with fibrinolysis, delayed PCI is associated with higher 30-day mortality (OR, 2.6; 95\% CI, 1.2-5.64) and 5-year mortality (OR, 2.03; 95\% CI, 1.1-5.64) [50, 51]. In patients with STEMI presenting less than $2 \mathrm{~h}$ after symptom onset for whom primary PCI will result in a delay of greater than $60 \mathrm{~min}$, the 2015 JRC guidelines suggest fibrinolysis over primary PCI (weak recommendation, low-quality evidence) [49, 52, 53]. Further investigation on delayed PCI versus fibrinolysis is needed.

\section{ED fibrinolysis, transport only for rescue $P C l$, routine early angiography, transport for $\mathrm{PCl}$ or only rescue $\mathrm{PCI}$}

In adult patients with STEMI in the ED of a hospital without PCI capabilities, some RCTs have shown that transfer without fibrinolysis to a PCI center for angiography is associated with lower 30-day mortality compared with immediate in-hospital fibrinolysis and only transfer for ischemia-driven PCI in the first $24 \mathrm{~h}$ (OR, 0.66; 95\% CI, 0.50-0.86) [54, 55]. For adult patients presenting with STEMI in the ED of a hospital not capable of performing PCI, the 2015 JRC guidelines recommend emergency transfer without fibrinolysis to a PCI center as opposed to immediate in-hospital fibrinolysis and transfer only for rescue PCI (strong recommendation, moderate-quality evidence). On the other hand, some RCTs have shown no difference in 30-day mortality between immediate in-hospital fibrinolysis and routine transfer for angiography compared with transfer to a PCI center (OR, 0.84; 95\% CI, 0.24-2.98) [49, 56]. They suggest fibrinolytic therapy with routine transfer for angiography as an alternative to immediate transfer to PCI (weak recommendation, very low-quality evidence). Some RCTs have shown no difference in 30-day and 1-year mortality between either immediate inhospital fibrinolysis and routine transfer for angiography at 3 to $6 \mathrm{~h}$ (or up to $24 \mathrm{~h}$ ) and immediate in-hospital fibrinolysis and only transfer for ischemia-driven PCI (rescue PCI) (OR, 0.96; 95\% CI, 0.64-1.44, OR 0.54; 95\% CI, 0.16-1.89, respectively) [49, 57, 58]. Thus, for patients with STEMI who underwent ED fibrinolysis when primary PCI was not available on-site, the 2015 JRC guidelines suggest transport for early routine angiography in the first 3 to $6 \mathrm{~h}$ (or up to $24 \mathrm{~h}$ ) rather than only transport for ischemia-guided angiography (weak recommendation, moderate-quality evidence).

The current evidence indicates that PCI from 3 to $24 \mathrm{~h}$ after fibrinolysis reduces reinfarction. The optimal timing within this time window has not been established. Similarly, the optimal management is unclear for patients after fibrinolysis in remote areas where transport to PCI is difficult or prolonged [54, 58-64].

\section{Medications for ACS}

To reduce the incidence of major adverse cardiac event and improve long-term survival, some additional medical therapies have been proposed. However, most of the data supporting the use of these therapies were gathered from patients after admission. To date, there is no evidence on which additional medical therapies in the prehospital or ED setting are important for patients with ACS.

\section{Antiarrhythmics}

Avoiding preventive administration of antiarrhythmics is reasonable in patients with ACS.

\section{B-blockers}

Avoiding routine intravenous administration of $\beta$-blockers during the initial prehospital or ED evaluation is reasonable for patients with ACS. For patients with ACS, there is no evidence to support routine intravenous administration of $\beta$-blockers during the initial prehospital or ED evaluation. Intravenous administration of $\beta$-blockers may be reasonable for selected patients 
with severe hypertension and tachycardia [65, 66]. On the other hand, contraindications to $\beta$-blockers include moderate to severe left ventricular failure, pulmonary edema, bradycardia, and hypotension. The effect of early $\beta$-blocker administration has not been fully studied in the primary PCI era.

After the patient is stabilized, starting an oral agent of $\beta$-blocker at a low dose before discharge is reasonable [67]. A recent multicenter registry of AMI in the PCI era has shown that $\beta$-blockers are associated with reduced mortality during long-term follow-up [68].

\section{Angiotensin-converting enzyme inhibitors (ACE-Is) and angiotensin II receptor blockers (ARBs)}

ACE-I and ARB administration after admission is known to reduce mortality in patients with acute myocardial infarction [69, 70]. However, there is insufficient evidence to support the routine administration of ACE-Is and ARBs in the prehospital and ED settings.

\section{HMG-CoA reductase inhibitors (statins)}

Statin therapy for patients with ACS soon after admission is reasonable in patients without contraindications [71]. Statins should be continued for patients with ACS who are already being treated with statins [72].

\section{Hospital reperfusion decisions after return of spontaneous circulation (ROSC) $\mathrm{PCl}$ after ROSC with or without ST elevation}

After ROSC, some observational studies have shown that emergency cardiac catheterization in patients with ST elevation is associated with increased in-hospital survival (OR, 0.35; 95\% CI, 0.31-0.41) and favorable neurological survival (OR 2.54; 95\% CI, 2.17-2.99) compared with catheterization laboratory evaluation later in the hospital stay or no catheterization [73-76]. On the other hand, after ROSC in patients without ST elevation, two observational studies have shown the benefit of emergency cardiac catheterization on in-hospital mortality (OR, 0.51; 95\% CI, 0.35-0.73) and favorable neurological survival (OR 1.96; 95\% CI, 1.35-2.85) compared with catheterization laboratory evaluation later in the hospital stay or no catheterization [73, 76]. Thus, the 2015 JRC guidelines recommend emergency cardiac catheterization laboratory evaluation rather than cardiac catheterization later in the hospital stay or no catheterization in selected adult patients with ROSC after out-of-hospital cardiac arrest of suspected cardiac origin with ST elevation (strong recommendation, low-quality evidence) or without ST elevation on ECG (weak recommendation, very low-quality evidence). In patients with ST elevation, a variety of factors were more likely to be associated with cardiac catheterization: male gender, younger age, ventricular fibrillation as the presenting cardiac arrest rhythm, witnessed arrest, bystander cardiopulmonary resuscitation (CPR), and being supported with vasopressors or left ventricular assist devices. Patient characteristics that were less likely to be associated with angiography were diabetes mellitus, renal failure, and heart failure. On the other hand, in patients without ST elevation, a variety of factors such as patient age, CPR duration, hemodynamic instability, presenting cardiac rhythm, neurologic status upon hospital arrival, and perceived likelihood of cardiac etiology influenced the decision for intervention. Further investigation is needed to confirm the benefit seen in the first two observational studies. Ideally, randomized studies would help identify if there are certain subgroups of patients that would benefit more from angiography after ROSC.

\section{Mechanical support for ACS with cardiogenic shock or cardiac arrest}

ACS patients are often hemodynamically unstable. Management of these patients can be challenging. The use of mechanical support is taken into consideration for ACS patients with cardiogenic shock, defined as systolic blood pressure of less than $90 \mathrm{mmHg}$, use of catecholamines to maintain a systolic pressure of at least $90 \mathrm{mmHg}$, clinical signs of pulmonary congestion, or signs of impaired organ perfusion. In ACS patients with shock, use of an intra-aortic balloon pump (IABP), percutaneous left ventricular support device (Impella ${ }^{\circ}$, Abiomed, Danvers, Massachusetts), or veno-arterial extracorporeal membrane oxygenation (VA-ECMO) can be considered. Although the American Heart Association and European Society of Cardiology guidelines have downgraded the use of IABP $[36,77]$, the Japanese Cardiology Society guidelines give the use of IABP for cardiogenic shock a class I recommendation because percutaneous left ventricular support device (Impella $\left.{ }^{\circ}\right)$ was not yet approved in Japan at the time. Percutaneous left ventricular support device $\left(\right.$ Impella ${ }^{\circ}$ ) has been approved in Japan since 2017. Further accumulation of

Table 3 Ways to improve systems of care for acute coronary syndrome

- Emergency physician calls for the catheterization team

- Single call to a central operator

- Real-time data feedback

- Institutional commitment

- Team-based approach

- Catheterization team arrival within 20 min of being called

- Having an interventional cardiologist immediately available at the hospital

It is reasonable for hospitals to consider these measures to improve systems of care for acute coronary syndrome 


\section{Reperfusion goals: Symptom onset-to-reperfusion $<120 \mathrm{~min}$ \\ EMS-to-drug $<30 \mathrm{~min}$ \\ EMS-to-balloon $<90$ min}
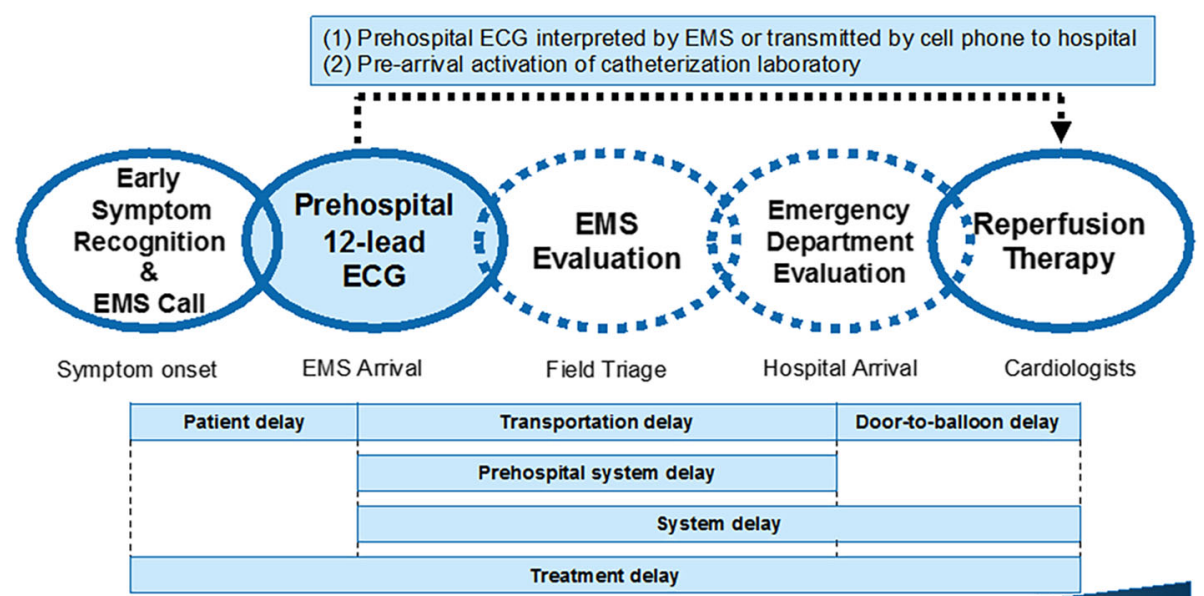

Increasing loss of myocytes

Fig. 2 Time-course goals for reperfusion in acute coronary syndrome. The target time from symptom onset to reperfusion is $\leq 120$ min. The target time from first medical contact to fibrinolysis is $\leq 30 \mathrm{~min}$. The target time from first medical contact to percutaneous coronary intervention is $\leq$ $90 \mathrm{~min}$. However, there are many factors that can delay reperfusion. To prevent delay, we must educate citizens to call EMS as soon as symptoms occur. To prevent transportation, prehospital system, and door-to-balloon delays, prehospital 12-lead ECG is recommended. Prehospital ECG can shorten the duration of EMS evaluation (hospital selection) and emergency department evaluation (decision to reperfuse). ECG electrocardiogram, EMS emergency medical services

clinical data in Japan is needed. On the other hand, the 2015 JRC guidelines suggest that VA-ECMO is a reasonable rescue therapy for selected patients with cardiac arrest refractory to conventional CPR (weak recommendation, very low-quality evidence) [78, 79]. In patients with cardiac arrest due to ACS, VA-ECMO may allow providers additional time to treat acute coronary artery occlusion [80]. However, these techniques require adequate vascular access and specialized equipment.

\section{Health care system interventions for ACS Prehospital notification for activation of the cardiac catheterization laboratory and calling for the catheterization team}

To prepare for primary PCI, the 2015 JRC guidelines recommend prehospital notification to activate the cardiac catheterization laboratory and calling for the catheterization team (strong recommendation, very low-quality evidence). Some observational studies have shown that prehospital activation of the catheterization team reduces 30-day mortality (OR, 0.41; 95\% CI, 0.30-0.56) [7, 10, 81]. Establishment of a health care system in the prehospital and ED settings is needed (Table 3).

\section{Conclusion}

Several systems-related strategies have been developed to improve quality of care for patients with ACS and reduce reperfusion delays for patients with STEMI. Some strategies that focus on patients identified as having ACS in the prehospital and ED settings (Fig. 2) include the use of prehospital 12-lead ECG and time-saving strategies to facilitate early diagnosis and rapid treatment for patients with STEMI. Recently, PCI technique has become established. Thus, we must construct a system of health care to achieve early reperfusion in the prehospital and ED settings to reduce mortality in patients with ACS.

\section{Abbreviations}

ACE-Is: Angiotensin-converting enzyme inhibitors; ACS: Acute coronary syndrome; ACT: Activated clotting time; ARBs: Angiotensin II receptor blockers; COSTR: Consensus on Cardiopulmonary Resuscitation and Cardiovascular Care Science with Treatment Recommendations; CPR: Cardiopulmonary resuscitation; CT: Computed tomography; ECG: Electrocardiogram; ED: Emergency department; EMS: Emergency medical service; GRACE: Global Registry of Acute Coronary Events; hs-cTn: High-sensitivity cardiac troponin; IABP: Intra-aortic balloon pump; JRC: Japan Resuscitation Council; MR: Magnetic resonance;

NSAID: Non-steroidal anti-inflammatory drug; NSTEMI: Non-ST-elevation myocardial infarction; PCl: Percutaneous coronary intervention; ROSC: Return of spontaneous circulation; RV: Right ventricular; STEMI: ST-elevation myocardial infarction; TIMI: Thrombolysis in Myocardial Infarction Trial; 
UFH: Unfractionated heparin; VA-ECMO: Veno-arterial extracorporeal membrane oxygenation

\section{Acknowledgements}

We thank the members of the 2015 JRC resuscitation guidelines working group

\section{Funding}

None

\section{Availability of data and materials}

As my article is a review, this is not applicable in this session.

\section{Authors' contributions}

TN wrote the main manuscript. YT critically reviewed and revised the manuscript for intellectual content. Both authors read and approved the final manuscript.

\section{Ethics approval and consent to participate}

Not applicable in this session.

\section{Consent for publication}

Not applicable in this session.

\section{Competing interests}

The authors declare that they have no competing interests.

\section{Publisher's Note}

Springer Nature remains neutral with regard to jurisdictional claims in published maps and institutional affiliations.

\section{Received: 15 October 2017 Accepted: 21 February 2018}

\section{Published online: 15 March 2018}

\section{References}

1. Lefler LL, Bondy KN. Women's delay in seeking treatment with myocardial infarction: a meta-synthesis. J Cardiovasc Nurs. 2004;19:251-68.

2. Moser DK, Kimble LP, Alberts MJ, et al. Reducing delay in seeking treatment by patients with acute coronary syndrome and stroke: a scientific statement from the American Heart Association Council on cardiovascular nursing and stroke council. Circulation. 2006;114:168-82.

3. Aragam KG, Tamhane UU, Kline-Rogers E, et al. Does simplicity compromise accuracy in ACS risk prediction? A retrospective analysis of the TIMI and GRACE risk scores. PLoS One. 2009:4:e7947.

4. de Araujo GP, Ferreira J, Aguiar C, Seabra-Gomes R. TIMI, PURSUIT, and GRACE risk scores: sustained prognostic value and interaction with revascularization in NSTE-ACS. Eur Heart J. 2005;26:865-72.

5. Canto JG, Rogers WJ, Bowlby LJ, French WJ, Pearce DJ, Weaver WD. The prehospital electrocardiogram in acute myocardial infarction: is its full potential being realized? National Registry of Myocardial Infarction 2 Investigators. J Am Coll Cardiol. 1997;29:498-505.

6. Terkelsen CJ, Lassen JF, Norgaard BL, et al. Reduction of treatment delay in patients with ST-elevation myocardial infarction: impact of pre-hospital diagnosis and direct referral to primary percutanous coronary intervention. Eur Heart J. 2005:26:770-7.

7. Carstensen S, Nelson GC, Hansen PS, et al. Field triage to primary angioplasty combined with emergency department bypass reduces treatment delays and is associated with improved outcome. Eur Heart J. 2007;28:2313-9.

8. Brown DW, Gauvreau K, Powell AJ, et al. Cardiac magnetic resonance versus routine cardiac catheterization before bidirectional Glenn anastomosis in infants with functional single ventricle: a prospective randomized trial. Circulation. 2007;116:2718-25.

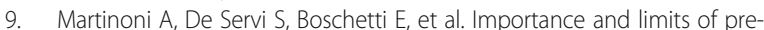
hospital electrocardiogram in patients with ST elevation myocardial infarction undergoing percutaneous coronary angioplasty. Eur J Cardiovasc Prev Rehabil. 2011;18:526-32

10. Sorensen JT, Terkelsen CJ, Norgaard BL, et al. Urban and rural implementation of pre-hospital diagnosis and direct referral for primary percutaneous coronary intervention in patients with acute ST-elevation myocardial infarction. Eur Heart J. 2011;32:430-6.
11. Chan AW, Kornder J, Elliott H, et al. Improved survival associated with prehospital triage strategy in a large regional ST-segment elevation myocardial infarction program. JACC CardiovasC Interv. 2012;5:1239-46.

12. Ong ME, Wong AS, Seet $C M$, et al. Nationwide improvement of door-toballoon times in patients with acute ST-segment elevation myocardial infarction requiring primary percutaneous coronary intervention with out-of-hospital 12-lead ECG recording and transmission. Ann Emerg Med. 2013;61:339-47.

13. Quinn T, Johnsen S, Gale CP, et al. Effects of prehospital 12-lead ECG on processes of care and mortality in acute coronary syndrome: a linked cohort study from the Myocardial Ischaemia National Audit Project. Heart. 2014;100: 944-50.

14. Ducas RA, Wassef AW, Jassal DS, et al. To transmit or not to transmit: how good are emergency medical personnel in detecting STEMI in patients with chest pain? Can J Cardiol. 2012;28:432-7.

15. Trivedi K, Schuur JD, Cone DC. Can paramedics read ST-segment elevation myocardial infarction on prehospital 12-lead electrocardiograms? Prehosp Emerg Care. 2009;13:207-14.

16. Lee $\mathrm{CH}$, Van Gelder CM, Cone DC. Early cardiac catheterization laboratory activation by paramedics for patients with ST-segment elevation myocardial infarction on prehospital 12-lead electrocardiograms. Prehosp Emerg Care. 2010;14:153-8.

17. Young DR, Murinson M, Wilson C, et al. Paramedics as decision makers on the activation of the catheterization laboratory in the presence of acute ST-elevation myocardial infarction. J Electrocardiol. 2011:44:18-22.

18. Dorsch MF, Greenwood JP, Priestley C, et al. Direct ambulance admission to the cardiac catheterization laboratory significantly reduces door-to-balloon times in primary percutaneous coronary intervention. Am Heart J. 2008;155: 1054-8.

19. Aldous SJ, Richards AM, Cullen L, Than MP. Early dynamic change in high-sensitivity cardiac troponin $T$ in the investigation of acute myocardial infarction. Clin Chem. 2011:57:1154-60.

20. Parsonage WA, Greenslade $\mathrm{JH}$, Hammett CJ, et al. Validation of an accelerated high-sensitivity troponin T assay protocol in an Australian cohort with chest pain. Med J Aust. 2014;200:161-5.

21. Cullen L, Greenslade JH, Than M, et al. The new Vancouver Chest Pain Rule using troponin as the only biomarker: an external validation study. Am J Emerg Med. 2014:32:129-34.

22. Cullen L, Mueller C, Parsonage WA, et al. Validation of high-sensitivity troponin I in a 2-hour diagnostic strategy to assess 30-day outcomes in emergency department patients with possible acute coronary syndrome. J Am Coll Cardiol. 2013:62:1242-9.

23. Scheuermeyer FX, Wong H, Yu E, et al. Development and validation of a prediction rule for early discharge of low-risk emergency department patients with potential ischemic chest pain. CJEM. 2014;16:106-19.

24. Kelly AM, Klim S. Prospective external validation of an accelerated (2-h) acute coronary syndrome rule-out process using a contemporary troponin assay. Int J Emerg Med. 2014;7:42

25. Mahler SA, Miller CD, Hollander JE, et al. Identifying patients for early discharge: performance of decision rules among patients with acute chest pain. Int J Cardiol. 2013;168:795-802.

26. Hess EP, Brison RJ, Perry JJ et al. Development of a clinical prediction rule for 30-day cardiac events in emergency department patients with chest pain and possible acute coronary syndrome. Ann Emerg Med 2012;59:115-125 e1.

27. Hoffmann U, Truong QA, Schoenfeld DA, et al. Coronary $C T$ angiography versus standard evaluation in acute chest pain. N Engl J Med. 2012;367:299-308.

28. Miller CD, Hwang W, Case D, et al. Stress CMR imaging observation unit in the emergency department reduces 1-year medical care costs in patients with acute chest pain: a randomized study for comparison with inpatient care. JACC Cardiovasc Imaging. 2011;4:862-70

29. Miller CD, Hwang W, Hoekstra JW, et al. Stress cardiac magnetic resonance imaging with observation unit care reduces cost for patients with emergent chest pain: a randomized trial. Ann Emerg Med. 2010;56:209-19. e2

30. Rawles JM, Kenmure AC. Controlled trial of oxygen in uncomplicated myocardial infarction. Br Med J. 1976;1:1121-3.

31. Ukholkina GB, Kostianov I, Kuchkina NV, Grendo EP, Gofman la B. Effect of oxygenotherapy used in combination with reperfusion in patients with acute myocardial infarction. Kardiologiia. 2005;45:59.

32. Ranchord AM, Argyle R, Beynon R, et al. High-concentration versus titrated oxygen therapy in ST-elevation myocardial infarction: a pilot randomized controlled trial. Am Heart J. 2012;163:168-75. 
33. Stub D, Smith K, Bernard $\mathrm{S}$, et al. Air versus oxygen in ST-segment-elevation myocardial infarction. Circulation. 2015;131:2143-50.

34. Wilson AT, Channer KS. Hypoxaemia and supplemental oxygen therapy in the first 24 hours after myocardial infarction: the role of pulse oximetry. J R Coll Physicians Lond. 1997;31:657-61.

35. Hofmann R, James SK, Jernberg T, et al. Oxygen therapy in suspected acute myocardial infarction. N Engl J Med. 2017;377:1240-9.

36. O'Gara PT, Kushner FG, Ascheim DD, et al. 2013 ACCF/AHA guideline for the management of ST-elevation myocardial infarction: a report of the American College of Cardiology Foundation/American Heart Association Task Force on Practice Guidelines. Circulation. 2013;127:e362-425.

37. Meine TJ, Roe MT, Chen AY, et al. Association of intravenous morphine use and outcomes in acute coronary syndromes: results from the CRUSADE quality improvement initiative. Am Heart J. 2005;149:1043-9.

38. McGettigan P, Henry D. Cardiovascular risk and inhibition of cyclooxygenase: a systematic review of the observational studies of selective and nonselective inhibitors of cyclooxygenase 2. JAMA. 2006;296:1633-44.

39. Kearney PM, Baigent C, Godwin J, Halls H, Emberson JR, Patrono C. Do selective cyclo-oxygenase-2 inhibitors and traditional non-steroidal antiinflammatory drugs increase the risk of atherothrombosis? Meta-analysis of randomised trials. BMJ. 2006:332:1302-8

40. Every NR, Parsons LS, Hlatky M, Martin JS, Weaver WD. A comparison of thrombolytic therapy with primary coronary angioplasty for acute myocardial infarction. Myocardial Infarction Triage and Intervention Investigators. N Engl J Med 1996;335:1253-1260.

41. Zeymer U, Arntz HR, Mark B, et al. Efficacy and safety of a high loading dose of clopidogrel administered prehospitally to improve primary percutaneous coronary intervention in acute myocardial infarction: the randomized CIPAMI trial. Clin Res Cardiol. 2012;101:305-12.

42. Ducci K, Grotti S, Falsini G, et al. Comparison of pre-hospital $600 \mathrm{mg}$ or 900 $\mathrm{mg}$ vs. peri-interventional $300 \mathrm{mg}$ clopidogrel in patients with ST-elevation myocardial infarction undergoing primary coronary angioplasty. The Load\&Go randomized trial. Int J Cardiol. 2013;168:4814-6.

43. Montalescot G, van 't Hof AW, Lapostolle F, et al. Prehospital ticagrelor in ST-segment elevation myocardial infarction. N Engl J Med. 2014;371:1016-27.

44. Zijlstra F, Ernst N, de Boer MJ, et al. Influence of prehospital administration of aspirin and heparin on initial patency of the infarct-related artery in patients with acute ST elevation myocardial infarction. J Am Coll Cardiol. 2002;39:1733-7.

45. Steg PG, Van 't Hof A, Hamm CW, et al. Bivalirudin started during emergency transport for primary PCI. N Engl J Med. 2013;369:2207-17.

46. Sejersten M, Nielsen SL, Engstrom T, Jorgensen E, Clemmensen P. Feasibility and safety of prehospital administration of bivalirudin in patients with STelevation myocardial infarction. Am J Cardiol. 2009;103:1635-40.

47. Hirschl MM, Mayr H, Erhart F, et al. Prehospital treatment of patients with acute myocardial infarction with bivalirudin. Am J Emerg Med. 2012;30:12-7.

48. Bonnefoy E, Lapostolle F, Leizorovicz A, et al. Primary angioplasty versus prehospital fibrinolysis in acute myocardial infarction: a randomised study. Lancet. 2002:360:825-9.

49. Armstrong PW, Committee WS. A comparison of pharmacologic therapy with/without timely coronary intervention vs. primary percutaneous intervention early after ST-elevation myocardial infarction: the WEST (Which Early ST-elevation myocardial infarction Therapy) study. Eur Heart J. 2006;27: $1530-8$

50. Westerhout CM, Bonnefoy E, Welsh RC, Steg PG, Boutitie F, Armstrong PW. The influence of time from symptom onset and reperfusion strategy on 1 year survival in ST-elevation myocardial infarction: a pooled analysis of an early fibrinolytic strategy versus primary percutaneous coronary intervention from CAPTIM and WEST. Am Heart J. 2011;161:283-90.

51. Bonnefoy E, Steg PG, Boutitie F, et al. Comparison of primary angioplasty and pre-hospital fibrinolysis in acute myocardial infarction (CAPTIM) trial: a 5-year follow-up. Eur Heart J. 2009;30:1598-606.

52. Thiele H, Eitel I, Meinberg C, et al. Randomized comparison of pre-hospitalinitiated facilitated percutaneous coronary intervention versus primary percutaneous coronary intervention in acute myocardial infarction very early after symptom onset: the LIPSIA-STEMI trial (Leipzig immediate prehospital facilitated angioplasty in ST-segment myocardial infarction). JACC Cardiovasc Interv. 2011;4:605-14.

53. Armstrong PW, Gershlick AH, Goldstein P, et al. Fibrinolysis or primary $\mathrm{PCl}$ in ST-segment elevation myocardial infarction. N Engl J Med. 2013; 368:1379-87.
54. Andersen HR, Nielsen TT, Rasmussen $\mathrm{K}$, et al. A comparison of coronary angioplasty with fibrinolytic therapy in acute myocardial infarction. N Engl J Med. 2003;349:733-42.

55. Perez de Arenaza D, Taneja AK, Flather M. Long distance transport for primary angioplasty vs immediate thrombolysis in acute myocardial infarction (PRAGUE-2 trial). Eur Heart J. 2003;24:1798.

56. Fernandez-Aviles F, Alonso JJ, Pena G, et al. Primary angioplasty vs. early routine post-fibrinolysis angioplasty for acute myocardial infarction with ST-segment elevation: the GRACIA-2 non-inferiority, randomized, controlled trial. Eur Heart J. 2007;28:949-60.

57. Scheller B, Hennen B, Hammer B, et al. Beneficial effects of immediate stenting after thrombolysis in acute myocardial infarction. J Am Coll Cardiol. 2003;42:634-41.

58. Widimsky P, Groch L, Zelizko M, Aschermann M, Bednar F, Suryapranata H. Multicentre randomized trial comparing transport to primary angioplasty vs immediate thrombolysis vs combined strategy for patients with acute myocardial infarction presenting to a community hospital without a catheterization laboratory. The PRAGUE study Eur Heart J. 2000;21:823-31.

59. Widimsky $P$, Budesinsky $T$, Vorac $D$, et al. Long distance transport for primary angioplasty vs immediate thrombolysis in acute myocardial infarction: final results of the randomized national multicentre trial-PRAGUE-2. Eur Heart J. 2003;24:94-104.

60. Dieker HJ, van Horssen EV, Hersbach FM, et al. Transport for abciximab facilitated primary angioplasty versus on-site thrombolysis with a liberal rescue policy: the randomised Holland Infarction Study (HIS). J Thromb Thrombolysis. 2006;22:39-45.

61. Dobrzycki S, Kralisz P, Nowak K, et al. Transfer with GP Ilb/llla inhibitor tirofiban for primary percutaneous coronary intervention vs. on-site thrombolysis in patients with ST-elevation myocardial infarction (STEMI): a randomized open-label study for patients admitted to community hospitals. Eur Heart J. 2007;28:2438-48.

62. Grines $\mathrm{CL}$, Westerhausen $\mathrm{DR} \mathrm{Jr}$, Grines $\mathrm{L} L$, et al. A randomized trial of transfer for primary angioplasty versus on-site thrombolysis in patients with high-risk myocardial infarction: the Air Primary Angioplasty in Myocardial Infarction study. J Am Coll Cardiol. 2002;39:1713-9.

63. Svensson $L$, Aasa $M$, Dellborg $M$, et al. Comparison of very early treatment with either fibrinolysis or percutaneous coronary intervention facilitated with abciximab with respect to ST recovery and infarct-related artery epicardial flow in patients with acute ST-segment elevation myocardial infarction: the Swedish Early Decision (SWEDES) reperfusion trial. Am Heart J. 2006;151:798 e1-7.

64. Vermeer F, Oude Ophuis AJ, vd Berg EJ, et al. Prospective randomised comparison between thrombolysis, rescue PTCA, and primary PTCA in patients with extensive myocardial infarction admitted to a hospital without PTCA facilities: a safety and feasibility study. Heart. 1999;82:426-31.

65. Chen ZM, Pan HC, Chen YP, et al. Early intravenous then oral metoprolol in 45,852 patients with acute myocardial infarction: randomised placebocontrolled trial. Lancet. 2005;366:1622-32.

66. Herlitz J, Edvardsson N, Holmberg S, et al. Goteborg Metoprolol Trial: effects on arrhythmias. Am J Cardiol. 1984;53:27D-31D.

67. Freemantle N, Cleland J, Young P, Mason J, Harrison J. Beta blockade after myocardial infarction: systematic review and meta regression analysis. BMJ. 1999:318:1730-7.

68. Goldberger JJ, Bonow RO, Cuffe M, et al. Effect of beta-blocker dose on survival after acute myocardial infarction. J Am Coll Cardiol. 2015;66:1431-41.

69. ISIS-4: a randomised factorial trial assessing early oral captopril, oral mononitrate, and intravenous magnesium sulphate in 58,050 patients with suspected acute myocardial infarction. ISIS-4 (fourth international study of infarct survival) collaborative group. Lancet 1995;345:669-685.

70. GISSI-3: effects of lisinopril and transdermal glyceryl trinitrate singly and together on 6-week mortality and ventricular function after acute myocardial infarction. Gruppo Italiano per lo studio della Sopravvivenza nell'infarto Miocardico. Lancet. 1994;343:1115-22.

71. Kayikcioglu M, Can L, Kultursay H, Payzin S, Turkoglu C. Early use of pravastatin in patients with acute myocardial infarction undergoing coronary angioplasty. Acta Cardiol. 2002:57:295-302.

72. Heeschen C, Hamm CW, Laufs U, et al. Withdrawal of statins increases event rates in patients with acute coronary syndromes. Circulation. 2002;105:1446-52.

73. Hollenbeck RD, McPherson JA, Mooney MR, et al. Early cardiac catheterization is associated with improved survival in comatose survivors of cardiac arrest without STEMI. Resuscitation. 2014;85:88-95. 
74. Mooney MR, Unger BT, Boland LL, et al. Therapeutic hypothermia after out-of-hospital cardiac arrest: evaluation of a regional system to increase access to cooling. Circulation. 2011;124:206-14.

75. Grasner JT, Meybohm P, Lefering R, et al. ROSC after cardiac arrest-the RACA score to predict outcome after out-of-hospital cardiac arrest. Eur Heart J. 2011;32:1649-56.

76. Bro-Jeppesen J, Kjaergaard J, Wanscher M, et al. Emergency coronary angiography in comatose cardiac arrest patients: do real-life experiences support the guidelines? Eur Heart J Acute Cardiovasc Care. 2012;1:291-301.

77. Ibanez B, James S, Agewall S, et al. ESC guidelines for the management of acute myocardial infarction in patients presenting with ST-segment elevation: the task force for the management of acute myocardial infarction in patients presenting with ST-segment elevation of the European Society of Cardiology (ESC). Eur Heart J. 2017;2017

78. Maekawa K, Tanno K, Hase M, Mori K, Asai Y. Extracorporeal cardiopulmonary resuscitation for patients with out-of-hospital cardiac arrest of cardiac origin: a propensity-matched study and predictor analysis. Crit Care Med. 2013:41:1186-96.

79. Sakamoto T, Morimura N, Nagao K, et al. Extracorporeal cardiopulmonary resuscitation versus conventional cardiopulmonary resuscitation in adults with out-of-hospital cardiac arrest: a prospective observational study. Resuscitation. 2014:85:762-8.

80. Yannopoulos D, Bartos JA, Raveendran G, et al. Coronary artery disease in patients with out-of-hospital refractory ventricular fibrillation cardiac arrest. J Am Coll Cardiol. 2017;70:1109-17.

81. Brown JP, Mahmud E, Dunford JV, Ben-Yehuda O. Effect of prehospital 12-lead electrocardiogram on activation of the cardiac catheterization laboratory and door-to-balloon time in ST-segment elevation acute myocardial infarction. Am J Cardiol. 2008;101:158-61.

\section{Submit your next manuscript to BioMed Central and we will help you at every step:}

- We accept pre-submission inquiries

- Our selector tool helps you to find the most relevant journal

- We provide round the clock customer support

- Convenient online submission

- Thorough peer review

- Inclusion in PubMed and all major indexing services

- Maximum visibility for your research

Submit your manuscript at www.biomedcentral.com/submit 